\title{
DESIGNING A DUAL-CHANNEL SUPPLY CHAIN NETWORK CONSIDERING DEPENDENT DEMAND AND DISCOUNT
}

\author{
Fatemeh Askarian-Amiri, Mohammad Mahdi Paydar*and Abdul Sattar Safaei
}

\begin{abstract}
Nowadays, organizations are faced with the growth of markets, satisfying customers' demand and empowering in competing with rivals imposed new communication channels. Along with the rapid advancement of the Internet, many suppliers are interested in creating an electronic channel in addition to the traditional retailer channel for direct market participation. This distribution system which includes retailer channels and direct channels is called a dual-channel supply chain. This study reviews a leather supply chain network that has created a discounted online channel to expand its market share. In this study, a multi-period multi-product mathematical model is developed to maximize the profit and examine the effect of different discount schemes on demand and sales. To verify the proposed model, a real-world case study is conducted. The sensitivity analyses examined the important model parameters. The obtained results show that the responsiveness of the main retailers could be more than $95 \%$. According to the sensitivity analysis, an appropriate discount rate is reported in the direct channel.
\end{abstract}

Mathematics Subject Classification. 90Bxx.

Received October 21, 2019. Accepted July 9, 2020.

\section{INTRODUCTION}

Over the past two decades, managers have witnessed a period of great global change due to advances in technology, globalization of markets and new economic and political conditions. With the rise of competitors, companies have been forced to improve their internal organizational processes to stay on the scene of global competition [5]. Supply chain management is one of the important scientific debates that the recent developments in the industry have been owed. Effective supply chain management is one of the main factors in companies, while the use of information technology in supply chain activities has increased the potential for value creation in the chain [6]. In this context, the internet has expanded the concept of the multi-channel supply chain with its features. The purpose of two or more channels is to make the supply chain network faster and more efficient with the customer, more environmentally friendly. The goal of the multi-channel supply chain is also to find different combinations that can be achieved by changing the methods of purchasing, pricing, shipping and distribution [8].

A two-channel supply chain is a multi-channel supply chain that has two traditional and online channels. Classifying markets and dividing them and their customers into two categories, in terms of how they relate to the supply chain, is a topic that is considered in designing the two-channel supply chain. Thus, two direct

Keywords. Supply chain, dual-channel, dependent demand, discount, leather products.

Department of Industrial Engineering, Babol Noshirvani University of Technology, Babol, Iran.

*Corresponding author: paydar@nit.ac.ir 
and indirect communication channels are formed. In the direct communication channel that is usually created between markets and manufacturers, communication is modern, through virtual networks or the Internet. This is done to increase the speed of receiving and sending orders and to increase the level of service in the chain. In the traditional indirect channel, the chain continues to be maintained through distributors with markets and customers. Each channel usually has its own specific demand and conditions that entering pricing can increase the differences between channels and customers [25].

In recent years, due to the increasing consumption and interest of consumers in buying leather products due to their quality, variety, beauty and durability, their market has increased. As a result, many factories have begun to produce leather products such as bags, shoes, clothing and other leather goods, which has created competition among manufacturers, distributors and retailers. Competition in sales is one of the important issues in the leather supply chain, so many manufacturers and retailers have been thinking of creating a new channel for selling their products to maintain their market share, online or direct selling [21].

Some companies, in addition to selling through retailers, sell some of their products through their website. A number of these retailers, called "outlet retailers", sell some of the products that are outdated and have high warehousing costs at lower prices so that their inventory at the factory reaches zero. Moreover, at different times, companies apply different discounts on their products, which increases competition between different channels and demand of different channels [4].

Since there is a bit of research on discounting and dependent demand in a two-channel supply chain, the present research focuses on the supply chain of leather products. As best of our knowledge, there is no research into the supply chain of this product with regard to channel-dependent demand and discounts. The purpose of this research is to develop a mathematical model for the supply chain network of leather goods with the aim of maximizing supply chain profit and determining the best discount time and discount rate. The proposed network planning horizon has several periods to examine the impact of different discounts on demand and sales. The direct channel always has a constant discount, which is increased during auction periods based on the amount of discount associated with the auction. The demand of the main retailers and the direct channel are interdependent and the increase or decrease in the price of one channel affects the demand of the other channel. But the demand for outlet retailers depends on the price of the channel itself.

The study consists of five sections. The second section discusses the studies of the dual-channel supply chain considering factors such as discounts, pricing, transportation mode and dependent demand. The third section provides a detailed description of the problem and the designed model and its components are fully specified. In the fourth section, the case study and input data are described in detail and the results of the model are analyzed. Finally, in the fifth section, the model's future suggestions are discussed.

\section{Literature REVIEW}

Given the importance of dual-channel supply chain problems, many researchers covered this issue in their studies. Here, some of the relevant researches are reported to find the research gaps and to highlight the novelties of the current study. For example, Chiang et al. [7] proposed a price-setting game between a producer and its independent retailers for a dual-channel supply chain. They stated that direct marketing rises profits over the retail channel and it could cause the manufacturer profitability. Applying a direct channel may not always be detrimental to the retailer because it will cause a wholesale price reduction, while it actuated as a limitation for the pricing behavior of retailers by the manufacturer. They claimed that utilizing both pull and push strategies by the manufacturer can be beneficial for the retailer and using several simulation experiments, attempted to give some directions and insights.

Moon et al. [22] addressed a dual-channel supply chain system using an optimization model under continuoustime conditions. Their proposed model covered inventory control and dynamic pricing problems and formed for a producer which seeks to maximize its profit through two channels. The model was solved by applying the Cournot-Nash-Bertrand game and differential quasi-variational inequality (DQVI). Finally, some suggestions are reported for the customer acceptance index and finding ideal strategies. Moreover, Li and Ma [17] proposed a 
dual-channel network and tried to consider delay decisions for retailers using a dynamical system and bifurcation theory. They applied some numerical simulation experiments to verify their framework. The obtained results imply that applying price-delay decisions makes the traditional channel more stable whereas it makes the network channel less stable. They reported that in the disordered state for the market, applying the mentioned decision could cause system stability in both traditional and network channels. They stated that considering the delay decision may cause system complexity. They applied profit index to evaluate the system's performance in different states and report their observations.

Liao et al. [19] formulated a multi-objective model for a dual-channel supply chain network. They aimed to; (1) minimize the facility location and inventory-related costs in the first objective function, (2) minimize the transportation cost in another objective function and (3) maximize the online customer's service to satisfy them in the final objective function. They employed some heuristic and metaheuristic algorithms to solve and compare the proposed multi-objective model. Moreover, they ordered the preference of these solutions using a multi-criteria decision-making tool (TOPSIS) method. Their framework and model were evaluated using several simulation experiments in various dimensions and some scenario analyses.

Huang et al. [12] examined the incentives to obtain demand information in a two-channel supply chain. They examined a dual-channel supply chain in which the manufacturer can offer a menu of contracts to encourage the retailer to purchase demand information.

Nekoiemehr et al. [23] investigated the role of lead time in a dual-channel supply chain. With the growth of e-commerce, many companies are adopting a dual-channel strategy of adding online sales to traditional retailer channels for easier access to products. In their paper, the lead time phrase for ordering online customers in a dual-channel two-stage supply chain is examined when there is a threshold for stated lead times. Mohan Modak and Kelle [20] examined dual-channel supply chain management under lead times and random pricedependent demand. They considered a by-level dual-channel supply chain with random demand dependent on sales prices and online lead time to maximize total supply chain profits. Taleizadeh et al. [27] examined pricing and product quality in a decentralized supply chain network with different channel structures using the game theory approach. Jamali and Rasti-Barzoki [14] examined a game theory approach to green and non-green pricing in sustainable and orderly competitive dual-channel supply chains. Xu et al. [28] coordinated a dualchannel supply chain with discount contracts under carbon emission provisions. They discussed the coordination of a two-channel supply chain regulated by the carbon emission capacity provisions. Li et al. [18] examined the effects of government subsidies for environmental products on the dual-channel supply chain. They examined the effects of government subsidies and alternative subsidies for environmental products on a two-channel supply chain with one manufacturer, one traditional retailer and one electronics retailer. Barzinpour and Taki [3] examined a two-channel design model in a green supply chain with regard to pricing and transportation mode selection. They considered a two-stage, single-product green supply chain network consisting of factories and distribution centers. Li et al. [16] examined the problems of dual-channel supply chain equilibrium in the retailer's services and fairness concerns. When a Manufacturer adds a direct channel, competition between the channels is an inevitable result. Manufacturers compete with retailers in the dual-channel supply chain. Yu et al. [29] investigated multi-objective models and a case study for supply chain network design for fresh products with two channels and fuzzy information. They explored the design of a dual-channel supply chain network including traditional and e-commerce channels for fresh products. Their proposed model is to solve network design integration problems related to the production, supply and sales of fresh crops, as well as to reduce supply chain operating costs and maximize demand satisfaction across supply chain nodes at the same time. Amini and $\mathrm{Li}[1]$ examined the impact of the dual market on supply chain configuration for new products. The main purpose of supply chain configuration is to identify a subset of supply chain partners that are at the highest level of productivity and responsiveness in the development, sourcing, production, distribution and support of the new product. Chia-Lin et al. [11] designed two-channel supply chain networks based on NSGA-II. They presented a two-stage multi-objective supply chain model with two sales channels. Their goal is to (1) determine the set of established distribution centers, (2) determine the set of customers that each DC should 
work with and how much inventory each DC should order and (3) determine the distribution paths for physical retailers or online retailers (All start and end are from the same DC).

On the other hand, Jafari et al. [13] proposed a dual-channel supply chain to price a product sold in both e-tail and retail channels. They applied a game-theoretic approach to gain optimal prices. One of the main assumptions of their framework is considering identical decision-making powers for retailers and manufacturers. In their framework, at first, the prices were tuned by the Nash game model and then the centralized model was solved to maximize the total profit. They measured their proposed supply chain coordination using a linear quantity discount schedule and reported the key results of the research.

Moreover, Fan et al. [9] addressed a dual-channel supply chain consist of several independent retail stores and an online store. They proposed some inventory optimization models under some conditions such as customer shift and inventory transforming. At first, they applied Markov chain theory to achieve optimal on-hand inventory and then optimized the total costs to gain the ideal inventory level. Finally, using some numerical simulation experiments, the impact of customer shift rate and inventory transforming rate on the inventory strategies is analyzed. Several managerial insights were reported using the obtained results and parametric analysis of the problem.

Table 1 shows the details of the present study and of the investigated research. Some of these details such as environmental and green concepts, pricing, production and lost sales are common in most studies, and some of them such as capacity constraint, discount, dependent demand and inventory are cited in fewer researches. Studies with case studies are identified as well. As can be seen from the table, there are few articles considering discounts and related demand in a dual-channel supply chain. The case of the current study is related to the supply chain of leather products. No comprehensive research has been conducted on the supply chain of leather products with regard to discounts and channel-dependent demand at the time of writing this research. This case study has been conducted in Iran which seeks to maximize the supply chain profits and determine the best time for discount and discount rates as well.

\section{Mathematical Formulation}

\subsection{Model description}

In recent years, due to increased customers' consumption of leather goods, the related market has been growing. In this regard, many factories have been designing and producing leather goods such as bags, shoes, clothing and other leather goods. It makes competition among manufacturers, distributors and retailers. Moreover, sales competition is one of the vital issues in the supply chain of leather goods, which is why many manufacturers and buyers have been thinking of creating additional channels for selling their products.

In the proposed supply chain network, there are a number of suppliers supplying different types of raw materials such as zippers, paints and adhesives and products are sold through two sales channels, namely, Internet sales (direct) and sales through retailers (indirect). In the direct channel, the product is shipped according to the amount of inventory and the size of the customer's order. In the indirect channel, sales are made through the main retailers and outlet retailers. In the proposed supply chain network, there are three categories for products, including bags, shoes and clothes. The proposed network planning horizon has several periods to examine the impact of various discounts on demand and sales. For example, there is a 12-month period in the one-year planning horizon. In the proposed network, at the end of the 6th and 11th months, a fraction of the inventory of the main retailer products will be sent to the outlet retailers. The direct channel always has a fixed discount which is increased by the discount rate associated with the auction at auction periods. The main retailers demand and the direct channel are dependent on each other, besides the increase or decrease in price in a channel affects the demand of the other channel. However, the demand for outlet retailers depends on its price. Likewise, the most important factor affecting the demand is quality. In the proposed model, the demand of both channels depend on the sales price and the quality of the products (in terms of damage at the production stage or out of fashion product), where the separation of the products in terms of quality through the constructing two sales channels is discussed (Fig. 1). 
DESIGNING A DUAL-CHANNEL SUPPLY CHAIN NETWORK

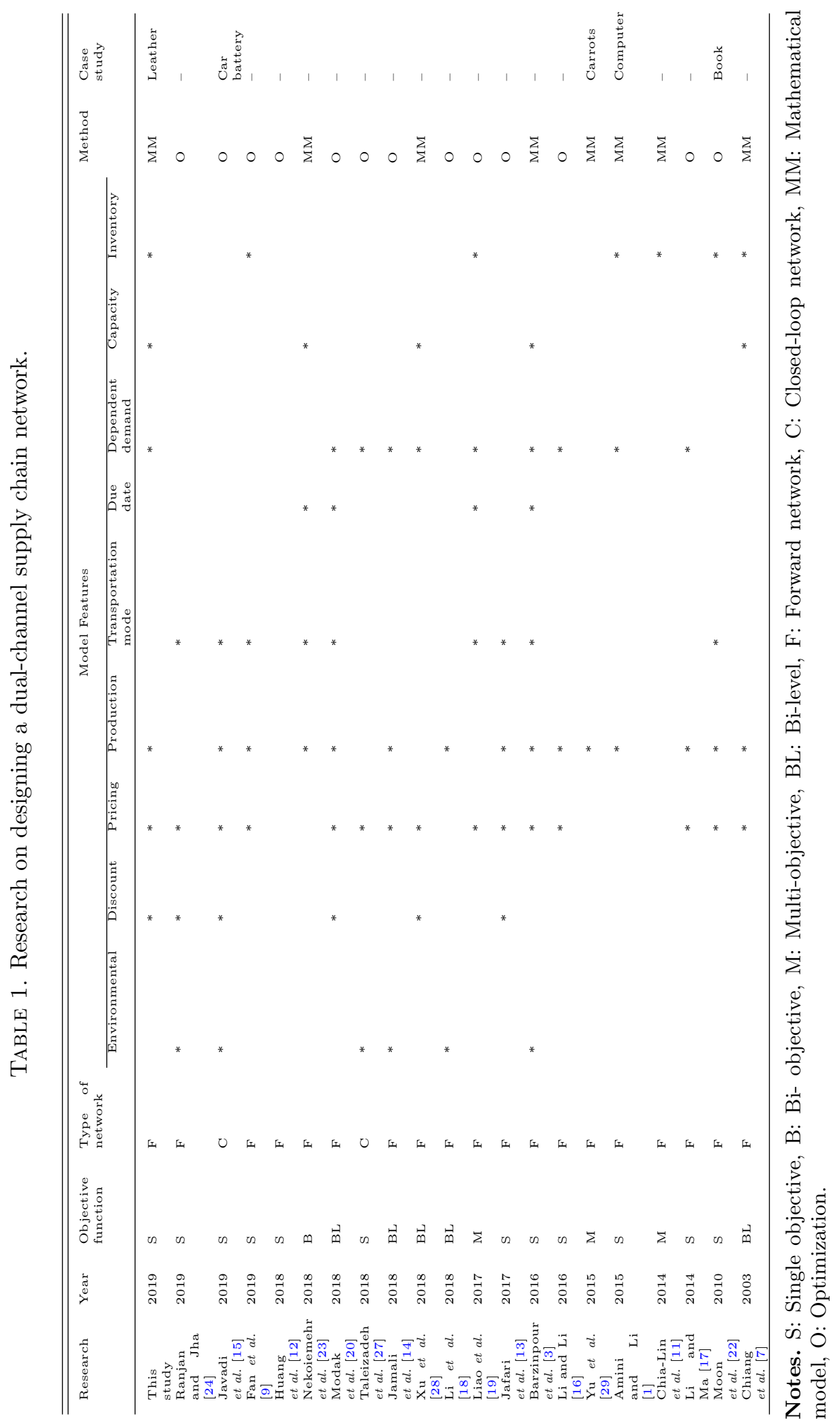




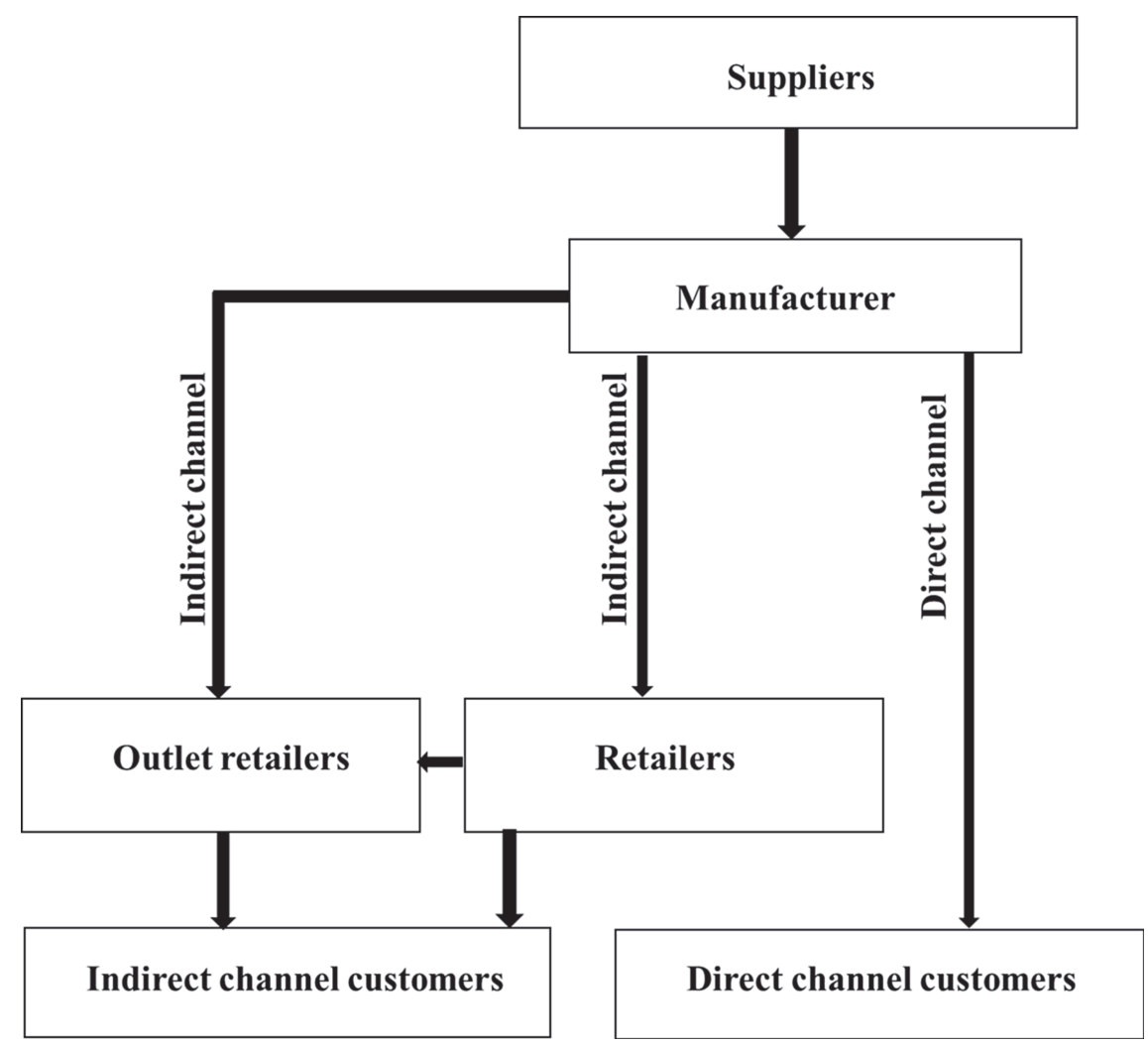

FIgURE 1. The proposed dual-channel supply chain network structure.

The following assumptions are considered to design the proposed supply chain network:

- The company has two separate sales channels for online and traditional sales.

- There is always a discount for customers who purchase online.

- Send to customers who purchase the product online is free.

- Outmoded products are sent to the outlet retailers from the main retailers.

- Outmoded products at outlet retailers are priced below the original retail price.

- Customer demand in both channels depends on the selling price of products.

\subsection{Mathematical model}

The following notations are used to formulate the mathematical model of the proposed model.

\section{Indices}

$\begin{array}{lll}s & \text { Index of suppliers } & (s=1,2, \ldots, S) \\ r & \text { Index of main retailers } & (r=1, \ldots, R) \\ o & \text { Index of outlet retailers } & (o=1, \ldots, O) \\ m & \text { Index of raw materials } & (m=1, \ldots, M) \\ p & \text { Index of products } & (p=1, \ldots, P) \\ d & \text { Index of discount types } & (d=1, \ldots, D) \\ t & \text { Index of periods } & (t=1, \ldots, T)\end{array}$




\section{Parameters}

\begin{tabular}{|c|c|}
\hline$\alpha_{p r}$ & Price-independent demand of main retailer $r$ for product $p$ \\
\hline $\mathrm{OD}_{p o t}^{\prime}$ & Discount-independent demand for outlet retailer $o$ for product $p$ in period $t$ \\
\hline & The sensitivity of demand related to the outlet retailers toward discount \\
\hline $\mathrm{MP}_{m s t}$ & Price of raw material $m$ provided from supplier $s$ during period $t$ \\
\hline $\mathrm{TS}_{m s}$ & Transportation cost per unit of raw material $m$ from the supplier $s$ to the factory \\
\hline $\mathrm{TR}_{p r}$ & Transportation cost per unit of product $p$ from the factory to main retailer $r$ \\
\hline $\mathrm{TO}_{p o}$ & Transportation cost per unit of product $p$ from the factory to outlet retailer $o$ \\
\hline $\mathrm{TRO}_{\text {pro }}$ & Transportation cost per unit of product $p$ from main retailer $r$ to outlet retailer $o$ \\
\hline $\mathrm{TD}_{p t}$ & Transportation cost per unit of product $p$ for customers through the direct channel in period $t$ \\
\hline$P_{p t}^{\prime}$ & Production cost per unit of product $p$ in the factory in period $t$ \\
\hline$h m_{m t}$ & Inventory holding cost per unit of raw material $m$ in the factory in period $t$ \\
\hline$h p_{p t}$ & Inventory holding cost per unit of product $p$ in the factory in period $t$ \\
\hline$h r_{p r t}$ & Inventory holding cost per unit of product $p$ for main retailer $r$ in period $t$ \\
\hline hopot & Inventory holding cost per unit of product $p$ for outlet retailer $o$ in period $t$ \\
\hline$p r_{p t}$ & Initial sale price per unit of product $p$ through main retailers in period $t$ \\
\hline po pt & Initial sale price per unit of product $p$ through outlet retailers in period $t\left(p o_{p t}<p r_{p t}\right)$ \\
\hline$C s_{m s}$ & Capacity of supplier $s$ for supplying raw material $m$ in each period \\
\hline$C m r_{m}$ & The capacity of holding raw material $m$ in the factory in each period \\
\hline$C m p_{p}$ & The capacity of holding product $p$ in the factory in each period \\
\hline$C r_{p r}$ & The capacity of holding product $p$ in main retailer $r$ in each period \\
\hline $\mathrm{Co}_{\mathrm{po}}$ & The capacity of holding product $p$ in outlet retailer $o$ in each period \\
\hline$B_{m p}$ & The required amount of raw material $m$ for producing each unit of product $p$ \\
\hline$f_{p t}$ & A fraction of product $p$ sent to outlet retailers from the factory in period $t$ \\
\hline $\mathrm{MD}_{t}$ & Cost of supporting and maintaining the direct channel in period $t$ \\
\hline$D r_{d p t}$ & Rate of discount type $d$ for product $p$ in period $t$ \\
\hline$d_{p t}^{\prime}$ & Rate of discount for product $p$ in the direct channel in period $t$ \\
\hline$\sigma$ & A fraction of income that is the share of the main retailer $(\sigma<1)$ \\
\hline$\gamma_{1}$ & Price-demand elasticity of main retailers \\
\hline$\gamma_{2}$ & Price-demand elasticity of the direct channel \\
\hline$\lambda_{1}$ & Substitutability elasticity of demand from retailers to the direct channel \\
\hline$\lambda_{2}$ & Substitutability elasticity of demand from the direct channel to retailers \\
\hline $\operatorname{Ir} 0_{p r}$ & Initial inventory of product $p$ in main retailer $r$ \\
\hline $\operatorname{Im} 0_{m}$ & Initial inventory of raw material $m$ in the factory \\
\hline$I p 0_{p}$ & Initial inventory of product $p$ in the factory \\
\hline$I 00_{p o}$ & Initial inventory of product $p$ in outlet retailer $o$ \\
\hline $\mathrm{GD}_{t}$ & ximum fraction of main retailers inventory sent to outlet retailes \\
\hline & ig posicive number \\
\hline
\end{tabular}

\section{Decision variables}

$\mathrm{QS}_{m s t} \quad$ The amount of raw material $m$ purchased from supplier $s$ by the factory in period $t$

$\mathrm{QM}_{p t} \quad$ The amount of product $p$ produced in the factory in period $t$

$\mathrm{QR}_{\text {prt }} \quad$ The amount of product $p$ sent from the factory to the main retailer $r$ in period $t$

$\mathrm{QO}_{\text {pot }} \quad$ The amount of product $p$ sent from the factory to outlet retailer $o$ in period $t$

$\mathrm{QD}_{p t}$

$\mathrm{QRO}_{\text {prot }}$

$\mathrm{IM}_{m t}$ The amount of product $p$ sent from factory to customer through the direct channel in period $t$

$\mathrm{IP}_{p t}$ The amount of product $p$ sent from main retailer $r$ to outlet retailer $o$ in period $t$

The inventory of raw material $m$ in the factory at the end of period $t$

The inventory of product $p$ in the factory at the end of period $t$ 
$\mathrm{IR}_{p r t} \quad$ The inventory of product $p$ in main retailer $r$ at the end of period $t$

$\mathrm{IO}_{\text {pot }} \quad$ The inventory of product $p$ in outlet retailer $o$ at the end of period $t$

$\mathrm{RD}_{\text {prt }} \quad$ Customers demand from the main retailer $r$ for product $p$ in period $t$

$\mathrm{OD}_{\text {pot }}$ Customers demand from the outlet retailer $o$ for product $p$ in period $t$

$\mathrm{DD}_{p t} \quad$ Customers demand from the direct channel for product $p$ in period $t$

$\mathrm{PRD}_{p t} \quad$ Price of each unit of product $p$ sold by main retailers in period $t$

$\mathrm{POD}_{p t}$ Price of each unit of product $p$ sold by outlet retailers in period $t$

$\mathrm{PDD}_{p t}$ Price of each unit of product $p$ sold by the factory through the direct channel in period $t$

$L_{d t} \quad 1$ If discount type $d$ is considered in period $t, 0$ otherwise

$\mathrm{SR}_{\text {prt }} \quad$ Number of product $p$ sold by the main retailer $r$ in period $t$

$\mathrm{SO}_{\text {pot }} \quad$ Number of product $p$ sold by the outlet retailer $o$ in period $t$

\section{Objective function}

$$
\begin{aligned}
\text { Max } Z= & \text { Revenue }- \text { Costs } \\
\text { Revenue }= & \sum_{p} \sum_{r} \sum_{t}(1-\sigma) \mathrm{PRD}_{p t} \mathrm{SR}_{p r t}+\sum_{p} \sum_{o} \sum_{t}(1-\sigma) \mathrm{POD}_{p t} \mathrm{SO}_{p o t}+\sum_{p} \sum_{t} \mathrm{PDD}_{p t} \mathrm{QD}_{p t} \\
\text { Costs }= & \sum_{m} \sum_{s} \sum_{t}\left(\mathrm{MP}_{m s t}+\mathrm{TS}_{m s}\right) \mathrm{QS}_{m s t}+\sum_{p} \sum_{t} P_{p t}^{\prime} \mathrm{QM}_{p t}+\sum_{p} \sum_{r} \sum_{t} \mathrm{TR}_{p r} \mathrm{QR}_{p r t} \\
& +\sum_{p} \sum_{o} \sum_{t} \mathrm{TO}_{p o} \mathrm{QO}_{p o t}+\sum_{p} \sum_{r} \sum_{o} \sum_{t} \mathrm{TRO}_{p r o} \mathrm{QRO}_{p r o t}+\sum_{m} \sum_{t} h m_{m t} \mathrm{IM}_{m t}+\sum_{p} \sum_{t} h p_{p t} \mathrm{IP}_{p t} \\
& +\sum_{p} \sum_{r} \sum_{t} h r_{p r t} \mathrm{IR}_{p r t}+\sum_{p} \sum_{o} \sum_{t} h o_{p o t} \mathrm{IO}_{p o t}+\sum_{p} \sum_{t} \mathrm{TD}_{p t} \mathrm{QD}_{p t}+\sum_{t} \mathrm{MD}_{t}
\end{aligned}
$$

The model objective function is shown in equations (3.1) to (3.3). The proposed objective function is to maximize total profit, which is equal to the difference between income and costs. The revenue of this proposed supply chain involves selling products through the main retailers, outlet retailer and direct channels. Costs include raw material purchase costs, production, inventory holdings at the factory and retailers, direct channel operating, shipping and product delivery through direct channels to the customer.

\section{Constraints}

$$
\begin{aligned}
& \mathrm{QM}_{p t} \leq C m p_{p} \quad \forall p, t \\
& \mathrm{QS}_{m s t} \leq C s_{m s} \quad \forall s, m, t \\
& \mathrm{IM}_{m t} \leq C m r_{m} \quad \forall m, t \\
& \mathrm{IP}_{p t} \leq C m p_{p} \quad \forall p, t \\
& \mathrm{IR}_{p r t} \leq C r_{p r} \quad \forall p, r, t \\
& \mathrm{IO}_{p o t} \leq C o_{p o} \quad \forall p, o, t \\
& \mathrm{IM}_{m t}+\sum_{p} B_{p m} \mathrm{QM}_{p t}=\sum_{s} \mathrm{QS}_{m s t}+\operatorname{Im} 0_{m} \quad \forall m, t=1 \\
& \mathrm{IM}_{m t}+\sum_{p} B_{p m} \mathrm{QM}_{p t}=\sum_{s} \mathrm{QS}_{m s t}+\mathrm{IM}_{m t-1} \quad \forall m, t \neq 1 \\
& I p 0_{p}+\mathrm{QM}_{p t}=\mathrm{IP}_{p t}+\sum_{r} \mathrm{QR}_{p r t}+\sum_{o} \mathrm{QO}_{p o t}+\mathrm{QD}_{p t} \quad \forall p, t=1 \\
& \mathrm{IP}_{p t-1}+\mathrm{QM}_{p t}=\mathrm{IP}_{p t}+\sum_{r} \mathrm{QR}_{p r t}+\sum_{o} \mathrm{QO}_{p o t}+\mathrm{QD}_{p t} \quad \forall p, t \neq 1
\end{aligned}
$$




$$
\begin{aligned}
& \mathrm{QR}_{p r t}+\operatorname{Ir} 0_{p r}=\mathrm{IR}_{p r t}+\mathrm{SR}_{p r t}+\sum_{o} \mathrm{QRO}_{\text {prot }} \quad \forall p, r, t=1 \\
& \mathrm{QR}_{\text {prt }}+\mathrm{IR}_{\text {prt-1 }}=\mathrm{IR}_{\text {prt }}+\mathrm{SR}_{\text {prt }}+\sum_{o} \mathrm{QRO}_{\text {prot }} \quad \forall p, r, t \neq 1 \\
& \mathrm{QO}_{p o t}+I o 0_{p o}+\sum_{r} \mathrm{QRO}_{\text {prot }}=\mathrm{IO}_{p o t}+\mathrm{SO}_{p o t} \quad \forall p, o, t=1 \\
& \mathrm{QO}_{p o t}+\mathrm{IO}_{\text {pot-1 }}+\sum_{r} \mathrm{QRO}_{\text {prot }}=\mathrm{IO}_{p o t}+\mathrm{SO}_{\text {pot }} \quad \forall p, o, t \neq 1 \\
& \sum_{o} \mathrm{QRO}_{\text {prot }+1} \leq \mathrm{GD}_{t} \times \mathrm{IR}_{\text {prt }} \quad \forall p, r, t \\
& \sum_{o} \mathrm{QO}_{p o t} \leq f_{p t} \mathrm{QM}_{p t} \quad \forall p, t \\
& \mathrm{SR}_{p r t} \leq \mathrm{RD}_{\text {prt }} \quad \forall p, r, t \\
& \mathrm{SO}_{\text {pot }} \leq \mathrm{OD}_{\text {pot }} \quad \forall p, o, t \\
& \mathrm{QD}_{p t} \leq \mathrm{DD}_{p t} \quad \forall p, t \\
& \mathrm{PRD}_{p t}=P r_{p t}-\left\lfloor\sum_{d} L_{d t} D r_{d p t} P r_{p t}\right\rfloor \quad \forall p, t \\
& \mathrm{POD}_{p t}=P o_{p t}-\left\lfloor\sum_{d} L_{d t} D r_{d p t} P o_{p t}\right\rfloor \quad \forall p, t \\
& \mathrm{PDD}_{p t}=\left\lfloor\left(1-d_{p t}^{\prime}\right) \times \mathrm{PRD}_{p t}\right\rfloor \quad \forall p, t \\
& L_{d t} \leq A \times D r_{d p t} \quad \forall d, p, t \\
& \sum_{d} L_{d t} \leq 1 \quad \forall t \\
& \mathrm{RD}_{p r t}=\alpha_{p r}-\lambda_{1} \mathrm{PRD}_{p t}+\gamma_{2} \mathrm{PDD}_{p t} \quad \forall p, r, t \\
& \mathrm{DD}_{p t}=\frac{\sum_{r} \alpha_{p r}}{r}-\lambda_{2} \mathrm{PDD}_{p t}+\gamma_{1} \mathrm{PRD}_{p t} \quad \forall p, t \\
& \mathrm{OD}_{p o t}=\mathrm{OD}_{p o t}^{\prime}\left(1+\mu \sum_{d} L_{d t} D r_{d p t}\right) \quad \forall p, o, t \\
& \mathrm{QD}_{p t}, \mathrm{SR}_{p r t}, \mathrm{SO}_{p o t}, \mathrm{PRD}_{p t}, \mathrm{POD}_{p t}, \mathrm{PDD}_{p t}, \mathrm{QR}_{p r t}, \mathrm{QO}_{p o t} \text {, } \\
& \mathrm{QM}_{p t}, \mathrm{QS}_{m s t}, \mathrm{QRO}_{\text {prot }}, \mathrm{IM}_{p o t}, \mathrm{IR}_{p r t}, \mathrm{IP}_{p t}, \mathrm{IM}_{m t}, \mathrm{RD}_{p r t}, R O_{p o t}, \quad \forall s, m, t, p, r, o \\
& \mathrm{DD}_{p t}, \mathrm{OD}_{p o t} \geq 0 \text {, Integer } \\
& L_{d t} \in\{0,1\} \quad \forall d, t .
\end{aligned}
$$

The model constraints are shown in equations (3.4) to (3.32). Constraints (3.4) to (3.9) are the capacity constraints, which include the capacity of the factory to store the produced products, the capacity of the supplier to supply raw materials, the capacity of the factory for storing raw materials, the capacity of the factory for storing the inventory and the capacity of the main retailers and outlet retailers for storing the products. Constraints (3.10) to (3.17) moderate the flow of inventories and new orders between facilities. Constraint (3.18) represents the maximum number of products shipped from the main retailer to the outlet retailer at different periods. Constraint (3.19) represents the maximum product shipped from the factory to the outlet retailers. Constraints (3.20) and (3.21) indicate that the amount of product sent from the factory to all of the retailers 
is at most equal to their demand. Constraint (3.22) shows that the number of products sent from the factory to the customers through the direct channel is at most equal to their demand. Constraints (3.23) to (3.25) calculate the sales prices of products in the main retailers, outlet retailers and direct channels, respectively considering the discount rate for each period. Constraint (3.26) indicates whether the discounts for the product in the intended period have been applied. Constraint (3.27) shows that at least one kind of discount can be considered for each product per product. Constraints (3.28) and (3.29) respectively indicate the dependence of direct channel demand and the total demand of the main retailers on the price of each other. Constraint (3.30) indicates the demand for outlet retailers and constraints (3.31) and (3.32) show the types of decision variables.

\subsection{Model linearization}

Since the income function in equation (3.2) is nonlinear, due to the multiplication of integer decision variables, it should be linearized. To linearize the multiplication of two bounded integer decision variables, first, it is necessary to transform one of them into a sum of several binary decision variables [10]. Then, we linearize the multiplication of the integer and binary decision variables through conventional methods $[2,26]$. First, we define the binary auxiliary decision variable named $X_{i p t}$ to linearize the first term of the income function.

$$
\mathrm{PRD}_{p t}=\sum_{i=1}^{N+1} 2^{i-1} X_{i p t} \quad \forall p, t .
$$

Based on equation (3.33), the integer decision variable $\mathrm{PRD}_{p t}$ is shown as the sum of the binary decision variable. The upper bound of this integer decision variable is the maximum initial price of the product in the main retailers. So:

$$
\begin{array}{ll}
\operatorname{PRD}_{p t} \leq \max _{\forall p, t}\left\{P r_{p t}\right\} & \forall p, t \\
\max _{\forall p, t}\left\{P r_{p t}\right\} \prec 2 & \forall p, t .
\end{array}
$$

Then, we define a new auxiliary integer decision variable named $Q x_{p r t}$ as follows:

$$
Q x_{p r t}=\mathrm{PRD}_{p t} \mathrm{SR}_{p r t} \quad \forall p, r, t .
$$

By inserting $\sum_{i=1}^{N+1} 2^{i-1} X_{i p t}$ instead of $\mathrm{PRD}_{p t}$, we have:

$$
Q x_{p r t}=\sum_{i=1}^{N+1} 2^{i-1} X_{i p t} \mathrm{SR}_{p r t} \quad \forall p, r, t .
$$

Equation (3.36) is also nonlinear and will be linearized by defining an auxiliary integer decision variable $Q z_{i p r t}$.

$$
Q z_{i p r t}=X_{i p t} \mathrm{SR}_{\text {prt }}
$$

which we have:

$$
Q x_{p r t}=\sum_{i=1}^{N+1} 2^{i-1} Q z_{i p r t} \quad \forall p, r, t
$$

and constraints (3.38) to (3.51) should be added to the original model:

$$
\begin{array}{ll}
Q z_{i p r t} \geq \mathrm{SR}_{\text {prt }}-A\left(1-X_{i p t}\right) & \forall i, p, r, t \\
Q z_{i p r t} \leq \mathrm{SR}_{\text {prt }}+A\left(1-X_{i p t}\right) & \forall i, p, r, t \\
Q z_{i p r t} \leq A X_{i p t} & \forall i, p, r, t \\
Q z_{i p r t}, Q x_{\text {prt }} \geq 0, \text { Integer } & \forall i, p, r, t .
\end{array}
$$


Linearization of the second and third terms of the income function is performed as the first term. To linearize the second term of the income function, we define the binary auxiliary decision variable named $Y_{i p t}$ :

$$
\mathrm{POD}_{p t}=\sum_{i=1}^{M+1} 2^{i-1} Y_{i p t} \quad \forall p, t .
$$

Based on equation (3.43), the integer decision variable $\mathrm{POD}_{p t}$ is shown as the sum of the binary decision variable $Y_{i p t}$. The upper bound of this integer decision variable is the maximum initial price of the product in the outlet retailers. So:

$$
\begin{array}{ll}
\operatorname{POD}_{p t} \leq \max _{\forall p, t}\left\{P o_{p t}\right\} & \forall p, t . \\
\max _{\forall p, t}\left\{P o_{p t}\right\} \prec 2^{M+1} & \forall p, t .
\end{array}
$$

Now, we define a new auxiliary integer decision variable named $G x_{p o t}$ as follows:

$$
G x_{p o t}=\mathrm{POD}_{p t} \mathrm{SO}_{p o t} .
$$

By inserting $\sum_{i=1}^{M+1} 2^{i-1} Y_{i p t}$ instead ofPOD ${ }_{p t}$, we have:

$$
G x_{p o t}=\sum_{i=1}^{M+1} 2^{i-1} Y_{i p t} \mathrm{SO}_{p o t} \quad \forall p, o, t .
$$

Equation (3.45) is also nonlinear and will be linearized by defining an auxiliary integer decision variable $G z_{i p r t}$.

$$
G z_{i p r t}=Y_{i p t} \mathrm{SO}_{\text {pot }}
$$

which we have:

$$
G x_{\text {pot }}=\sum_{i=1}^{M+1} 2^{i-1} G z_{\text {iprt }} \quad \forall p, o, t
$$

and constraints (3.47) to (3.50) should be added to the original model:

$$
\begin{array}{ll}
G z_{i p o t} \geq \mathrm{SO}_{\text {pot }}-A\left(1-Y_{i p t}\right) & \forall i, p, o, t \\
G z_{i p o t} \leq \mathrm{SO}_{\text {pot }}+A\left(1-Y_{i p t}\right) & \forall i, p, o, t \\
G z_{i p o t} \leq A Y_{i p t} & \forall i, p, o, t \\
G z_{i p o t}, G x_{p r t} \geq 0, \text { Integer } & \forall i, p, o, t .
\end{array}
$$

To linearize the third term of the income function, we define the binary auxiliary decision variable named $Z_{i p t}$ :

$$
\mathrm{PDD}_{p t}=\sum_{i=1}^{S+1} 2^{i-1} Z_{i p t} \quad \forall p, t .
$$

Based on equation (3.51), the integer decision variable $\mathrm{PDD}_{p t}$ is shown as the sum of the binary decision variable $Z_{i p t}$. The upper bound of this integer decision variable is the maximum initial price of the product in the online channel. So:

$$
\begin{array}{ll}
\mathrm{PDD}_{p t} \leq \max _{\forall p, t}\left\{P r_{p t}\right\} & \forall p, t \\
\max _{\forall p, t}\left\{P r_{p t}\right\} \prec 2^{S+1} & \forall p, t .
\end{array}
$$


Now, we define another auxiliary integer decision variable named $O x_{p t}$ as follows:

$$
O x_{p t}=\mathrm{PDD}_{p t} \mathrm{QD}_{p t}
$$

By inserting $\sum_{i=1}^{S+1} 2^{i-1} Z_{i p t}$ instead of $\mathrm{PDD}_{p t}$, we have:

$$
O x_{p t}=\sum_{i=1}^{S+1} 2^{i-1} Z_{i p t} \mathrm{QD}_{p t} \quad \forall p, t .
$$

Equation (3.54) is also nonlinear and will be linearized by defining an auxiliary integer decision variable $O z_{i p t}$.

$$
O z_{i p t}=Z_{i p t} \mathrm{QD}_{p t}
$$

which we have:

$$
O x_{p t}=\sum_{i=1}^{S+1} 2^{i-1} O z_{i p r t} \quad \forall p, r, t
$$

and constraints (3.56) to (3.59) should be added to the original model:

$$
\begin{array}{ll}
O z_{i p t} \geq \mathrm{QD}_{p t}-A\left(1-Z_{i p t}\right) & \forall i, p, t \\
O z_{i p t} \leq \mathrm{QD}_{p t}+A\left(1-Z_{i p t}\right) & \forall i, p, t \\
O z_{i p t} \leq A Z_{i p t} & \forall i, p, t \\
O z_{i p t}, O x_{p t} \geq 0, \text { Integer } & \forall i, p, t .
\end{array}
$$

Finally, the linearized income function (3.60) replaces the income function.

$$
\text { Revenue }=\sum_{p} \sum_{r} \sum_{t}(1-\sigma) Q x_{p r t}+\sum_{p} \sum_{o} \sum_{t}(1-\sigma) G x_{p o t}+\sum_{p} \sum_{t} O x_{p t} .
$$

Constraints (3.23) to (3.25) are also nonlinear because of the existence of the floor. For linearizing constraint (3.23), a new auxiliary integer decision variable $\operatorname{Yprd}_{p t}$ is defined as follows:

$$
Y p r d_{p t}=\left\lfloor\sum_{d} L_{d t} D r_{d p t} P r_{p t}\right\rfloor
$$

and constraints (3.61) to (3.63) are added to the original model:

$$
\begin{array}{lrl}
Y p r d_{p t} & \leq \sum_{d} L_{d t} D r_{d p t} \operatorname{Pr}_{p t} & \forall p, t \\
Y p r d_{p t}>\sum_{d} L_{d t} D r_{d p t} P r_{p t}-1 & \forall p, t \\
Y p r d_{p t} \geq 0, \text { Integer } & \forall p, t .
\end{array}
$$

To linearize constraint (3.24), a new auxiliary integer decision variable $Y p o d_{p t}$ is defined as follows:

$$
\operatorname{Ypod}_{p t}=\left\lfloor\sum_{d} L_{d t} D r_{d p t} P o_{p t}\right\rfloor
$$


and constraints (3.64) to (3.66) are added to the original model:

$$
\begin{array}{ll}
\operatorname{Ypod}_{p t} \leq \sum_{d} L_{d t} D r_{d p t} P o_{p t} & \forall p, t \\
\operatorname{Ypod}_{p t}>\sum_{d} L_{d t} D r_{d p t} P o_{p t}-1 & \forall p, t \\
\operatorname{Ypod}_{p t} \geq 0, \text { Integer } & \forall p, t .
\end{array}
$$

To linearize constraint (3.25), a new auxiliary integer decision variable $Y p d d_{p t}$ is defined as follows:

$$
Y p d d_{p t}=\left\lfloor\left(1-d_{p t}^{\prime}\right) \times \operatorname{PRD}_{p t}\right\rfloor
$$

and constraints (3.67) to (3.69) are added to the original model:

$$
\begin{array}{ll}
Y p d d_{p t} \leq\left(1-d_{p t}^{\prime}\right) \times \mathrm{PRD}_{p t} & \forall p, t \\
Y p d d_{p t}>\left(1-d_{p t}^{\prime}\right) \times \mathrm{PRD}_{p t}-1 & \forall p, t \\
Y p d d_{p t} \geq 0, \text { Integer } & \forall p, t .
\end{array}
$$

\section{Case Study}

\subsection{Case description}

The case study is a leather company in Iran that sells its products through online sales as well as sales through main retailers and outlet retailers. In this direct sales channel, products are delivered directly from the factory to the customer's address. The direct and indirect sales channels of the factory are completely separate from each other and retailers do not have information about online sales of the factory. All of the retailers supply their products from the factory every month, depending on their amount of sales. Outlet retailers have been located in two cities of Tehran and Mashhad. Some of the products that are outdated and have high storage costs are selling at a lower price until their inventory at the factory reaches to zero.

The case study planning horizon is one year which includes 12 one-month periods. The factory purchases seven main types of raw materials including raw leather, yarn, glue, button, paint, zipper and insole, from six suppliers in the provinces of Tehran and Khorasan Razavi to produce three categories of products, including shoes, bags and clothing. The factory sends its products to the retailers (through the indirect channel) and customers (through the direct channel) according to their demands. The types of discounts for the company is as follows: periodic auctions including a summer auction in the 6th month, a winter auction at the 11th month and auctions in different months based on national and religious occasions such as Father's Day and Mother's Day and also permanent discounts at outlet retailers and a ten percent discount on online sales that are influenced by periodic auctions. As stated, the outlet retailer stores are supplied from the factory and other main retailers. In this way, ending inventory of some periods will be sent to the outlet retailers from the main retailers particularly at the end of periods 6 and 11 and will be sold there lower than the original price (prediscount price at the main retailer). Also, a constant percentage of factory productions, which include older products or damaged products, is always sent to outlet retailers. Product prices in the outlet retailers and in the direct channel are also affected by targeted auctions and demands for direct channel and main retailers depend on each other.

\subsection{Input parameters}

The sensitivity of customers' demand for outlet retailers to discount $(\alpha)$ shows the effect of discounts on the demand of outlet retailers and in the supply chain of the proposed company is considered 0.7. The fraction of the income $(\sigma)$ that represents the share of the retailer from the sales' revenue of the products equals to 0.2. The price-demand elasticity of main retailers $\left(\gamma_{1}\right)$ shows the effect of products' price changes in the main retailer 
TABle 2. Price-independent demand of main retailers for products $\left(\alpha_{p r}\right)$.

\begin{tabular}{|c|c|c|c|c|c|c|c|c|c|c|c|c|c|c|c|c|c|c|c|c|c|c|c|}
\hline \multirow{2}{*}{ Products } & \multicolumn{21}{|c|}{ Main retailers } & \multirow{2}{*}{$\begin{array}{l}\text { Outlet } \\
(1)\end{array}$} & \multirow{2}{*}{$\begin{array}{l}\text { Outlet } \\
(2)\end{array}$} \\
\hline & 1 & 2 & 3 & 4 & 5 & 6 & 7 & 8 & 9 & 10 & 11 & 12 & 13 & 14 & 15 & 16 & 17 & 18 & 19 & 20 & 21 & & \\
\hline Bag & 1000 & 1500 & 1000 & 1000 & 1000 & 1000 & 1000 & 1000 & 1000 & 1000 & 1000 & 1000 & 1000 & 1000 & 1000 & 1000 & 1000 & 1000 & 1500 & 3000 & 5000 & 8000 & 7000 \\
\hline Shoes & 800 & 1200 & 800 & 800 & 800 & 800 & 800 & 800 & 800 & 800 & 800 & 800 & 800 & 800 & 800 & 800 & 800 & 800 & 1200 & 2500 & 4000 & 7000 & 8000 \\
\hline Clothes & 600 & 800 & 600 & 600 & 600 & 600 & 600 & 600 & 600 & 600 & 600 & 600 & 600 & 600 & 600 & 600 & 600 & 600 & 800 & 1500 & 3000 & 5500 & 5000 \\
\hline
\end{tabular}

TABLE 3. Discount-independent demand for outlet retailers for products in each period $\left(\mathrm{OD}_{\text {pot }}\right)$.

\begin{tabular}{llllllllllllll}
\hline \hline \multirow{2}{*}{ Products } & Outlet retailers & \multicolumn{1}{c}{ Periods } \\
\cline { 3 - 15 } & & 1 & 2 & 3 & 4 & 5 & 6 & 7 & 8 & 9 & 10 & 11 & 12 \\
\hline \multirow{2}{*}{ Bag } & Mashhad(2) & 200 & 200 & 250 & 200 & 200 & 350 & 200 & 200 & 200 & 200 & 350 & 300 \\
\multirow{3}{*}{ Shoes } & Tehran(1) & 150 & 150 & 200 & 150 & 200 & 300 & 200 & 200 & 200 & 200 & 300 & 250 \\
& Mashhad(2) & 250 & 250 & 300 & 250 & 250 & 400 & 250 & 250 & 250 & 250 & 400 & 350 \\
& Tehran(1) & 200 & 200 & 250 & 200 & 200 & 300 & 200 & 200 & 200 & 200 & 300 & 250 \\
& Mashhad(2) & 100 & 100 & 100 & 100 & 100 & 200 & 150 & 150 & 150 & 150 & 200 & 150 \\
& Tehran(1) & 80 & 80 & 80 & 80 & 80 & 150 & 120 & 120 & 120 & 120 & 120 & 120 \\
\hline
\end{tabular}

on the demand for products in the direct channel is considered 0.2. The price-demand elasticity of the direct channel $\left(\gamma_{2}\right)$ shows the effect of the products' price's changes in the direct channel on the demand for products in the main retailers is considered 0.2. The substitutability elasticity of demand from retailers to the direct channel $\left(\lambda_{1}\right)$ shows the effect of the products' price's change in the main retailers on the customers' transfer to the direct channel is considered 0.001. The substitutability elasticity of demand from the direct channel to retailers $\left(\lambda_{2}\right)$ shows the effect of the products' price's change in the direct channel to the customers' transfer to the main retailer and is considered 0.1 .

The production cost for bags, shoes and clothing for all periods $\left(P_{p t}^{\prime}\right)$ equal to 8,9 and 10, respectively. The initial inventory at the beginning of the planning horizon for all raw materials and all products equals to zero. Five percent of all the products are sent to the outlet retailers in all periods. The maximum fraction of the inventory of the main retailers that is sent to the outlet retailers at the end of the auction periods (periods 6 and 11) is 0.8 and the maximum fraction of the inventory of the main retailers that is sent to the outlet retailers at the end of the non-auctioned periods is 0.3 . The maintaining and operating costs for the direct channel in each period equal to 600. Direct channel customers at all periods have a discount of 10 percent for all products $\left(d_{p t}^{\prime}\right)$. Tables $2-16$ gives the data related to the presented problem. Tables 2 and 3 show the independent demand from the price of the main retailers and outlet retailers and the independent demand from the price of the direct channel equals to $\sum_{r} \alpha_{p r} / r$. In Table 4 , the price of raw materials is given based on their specific measurement units. The unit for measuring skin is the foot that each foot of the skin or leather has an area of $28 \mathrm{~cm}$ at $28 \mathrm{~cm}$. Zipper, button and footer measurement unit is the number. The measuring unit for yarn is meter and the glue and paint measuring unit is $10 \mathrm{~g}$. It is assumed that the selling price of raw materials by suppliers is the same at different periods. In Table 5, the initial price or the price before discount in retailers has been shown. In Table 6 , the costs associated with the products including transportation cost of the product to customers through the direct sales channel, production cost, inventory holding cost of products at the factory and retailers and inventory holding capacity of products at the factory are shown. Table 7 describes the raw material parameters. Because of the identical costs of Inventory holding of products at the factory at different periods for different retailers, duplicate numbers are discarded. Table 8 shows the required quantities of different types of raw materials for the production of each unit of the product. Table 9 shows the discount rate for different products in different periods for different types of discounts. 
TABLE 4. Price of raw materials provided from suppliers $\left(\mathrm{MP}_{m s t}\right)$.

\begin{tabular}{llllllll}
\hline \hline Raw material & $\begin{array}{l}\text { Raw } \\
\text { leather } \\
\text { (each } \\
\text { paw) }\end{array}$ & $\begin{array}{l}\text { Each } \\
\text { zipper }\end{array}$ & $\begin{array}{l}\text { Glue } \\
(10 \mathrm{~g})\end{array}$ & $\begin{array}{l}\text { Each } \\
\text { button }\end{array}$ & $\begin{array}{l}\text { Yarn } \\
\text { (each } \\
\text { meter })\end{array}$ & $\begin{array}{l}\text { Color } \\
(10 \mathrm{~g})\end{array}$ & $\begin{array}{l}\text { Each } \\
\text { insole }\end{array}$ \\
\hline Price & 2.8 & 0.4 & 0.15 & 0.2 & 0.1 & 0.7 & 1.5 \\
\hline
\end{tabular}

TABLE 5. The initial sales price per unit of product.

\begin{tabular}{lll}
\hline \hline Products & $\begin{array}{l}\text { The initial sale price of the product } \\
\text { through main retailers }\left(p r_{p t}\right)\end{array}$ & $\begin{array}{l}\text { The initial sale price of the product } \\
\text { through outlet retailers }\left(p o_{p t}\right)\end{array}$ \\
\hline Bag & 40 & 15 \\
Shoes & 35 & 20 \\
Clothes & 100 & 90 \\
\hline
\end{tabular}

TABLE 6. Product information.

\begin{tabular}{llllll}
\hline \hline Products & $\begin{array}{l}\text { Transportation } \\
\text { cost }\left(\mathrm{TD}_{p t}\right)\end{array}$ & $\begin{array}{l}\text { Production } \\
\text { cost }\left(P_{p}^{\prime}\right)\end{array}$ & $\begin{array}{l}\text { Inventory holding cost } \\
\text { of products in the fac- } \\
\text { tory }\left(h p_{p t}\right)\end{array}$ & $\begin{array}{l}\text { Inventory holding cost } \\
\text { of products for retailers } \\
\left(h r_{p r t}, h o_{p o t}\right)\end{array}$ & $\begin{array}{l}\text { Inventory holding } \\
\text { capacity of products in } \\
\text { the factory }\left(C m p_{p}\right)\end{array}$ \\
\hline Bag & 2 & 8 & 0.5 & 1 & 1000 \\
Shoes & 2 & 9 & 0.5 & 1.5 & 800 \\
Clothes & 3 & 10 & 1 & 1.5 & 600 \\
\hline
\end{tabular}

TABLE 7. Parameters related to raw materials in the factory.

\begin{tabular}{lll}
\hline \hline Raw materials & $\begin{array}{l}\text { Inventory holding cost of raw mate- } \\
\text { rial } s\left(\mathrm{hm}_{\mathrm{m} t}\right)\end{array}$ & $\begin{array}{l}\text { Inventory holding capacity of raw } \\
\text { materials }\left(\mathrm{Cmr}_{m}\right)\end{array}$ \\
\hline Raw leather & 0.5 & 3500 \\
Zipper & 0.1 & 2000 \\
Glue & 0.3 & 1000 \\
Button & 0.1 & 2000 \\
Yarn & 0.05 & 3000 \\
Color & 0.3 & 2000 \\
Insole & 0.2 & 1500 \\
\hline
\end{tabular}

\subsection{Results}

In this section, we examine the results of the problem solving according to the case study. The proposed model is conducted on a personal computer with Intel $\AA$ Core $^{\mathrm{TM}}$ i7-4710HQ CPU $2.50 \mathrm{GHz}$ and $8.00 \mathrm{~GB}$ RAM and Lingo version 9.0 in $10 \mathrm{~min}$. Table 10 indicates different periods in which there is at least one type of discount. According to Tables 9 and 10, it is obvious that the discount for bags and clothing is equal to $20 \%$ and the discount for shoes in periods 6 and 11 is equal to 30\%. Also, in the 9th and 12th periods, discounts of $15 \%$ and $20 \%$ for all products are considered, respectively. In Tables 11-13, the final price of products in retailers and direct channels in different periods is expressed. According to the results of Table 11, in periods 6 and 11, 
TABLE 8. The required amount of raw materials for producing each unit of products $\left(B_{m p}\right)$.

\begin{tabular}{llll}
\hline \hline \multirow{2}{*}{ Raw materials } & \multicolumn{3}{c}{ Products } \\
\cline { 2 - 4 } & Bag & Shoes & Clothes \\
\hline Raw leather & 1.5 & 3.5 & 6 \\
Zipper & 0 & 2 & 1 \\
Glue & 1 & 0.5 & 1 \\
Button & 0 & 2 & 10 \\
Yarn & 1.5 & 4 & 7 \\
Color & 2 & 1 & 2 \\
Insole & 2 & 0 & 0 \\
\hline
\end{tabular}

TABLE 9. Rate of discounts for products in each period $\left(D r_{d p t}\right)$.

\begin{tabular}{|c|c|c|c|c|c|c|c|c|c|c|c|c|c|}
\hline \multirow[t]{2}{*}{ Type of discount } & \multirow[t]{2}{*}{ Products } & \multicolumn{12}{|c|}{ Periods } \\
\hline & & 1 & 2 & 3 & 4 & 5 & 6 & 7 & 8 & 9 & 10 & 11 & 12 \\
\hline \multirow[t]{3}{*}{ Summer auction } & Bag & 0 & 0 & 0 & 0 & 0 & 0.2 & 0 & 0 & 0 & 0 & 0 & 0 \\
\hline & oes & 0 & 0 & 0 & 0 & 0 & 0.3 & 0 & 0 & 0 & 0 & 0 & 0 \\
\hline & Clothes & 0 & 0 & 0 & 0 & 0 & 0.2 & 0 & 0 & 0 & 0 & 0 & 0 \\
\hline \multirow[t]{3}{*}{ Winter auction } & Bag & 0 & 0 & 0 & 0 & 0 & 0 & 0 & 0 & 0 & 0 & 0.2 & 0 \\
\hline & Shoes & 0 & 0 & 0 & 0 & 0 & 0 & 0 & 0 & 0 & 0 & 0.3 & 0 \\
\hline & Clothe & 0 & 0 & 0 & 0 & 0 & 0 & 0 & 0 & 0 & 0 & 0.2 & 0 \\
\hline Nati & Bag & 0 & 0.15 & 0 & 0.2 & 0 & 0 & 0 & 0 & 0.15 & 0 & 0 & 0.2 \\
\hline religi & Shoe & 0 & 0.1 & 0 & 0.2 & 0 & 0 & 0 & 0 & 0.15 & 0 & 0 & 0.2 \\
\hline auction & Clothes & 0 & 0.15 & 0 & 0.2 & 0 & 0 & 0 & 0 & 0.15 & 0 & 0 & 0.2 \\
\hline
\end{tabular}

TABLE 10. Offered discounts at different periods $\left(L_{d t}\right)$.

\begin{tabular}{|c|c|c|c|c|c|c|c|c|c|c|c|c|}
\hline \multirow[t]{2}{*}{ Type of discount } & \multicolumn{12}{|c|}{ Periods } \\
\hline & 1 & 2 & 3 & 4 & 5 & 6 & 7 & 8 & 9 & 10 & 11 & 12 \\
\hline Summer auction & 0 & 0 & 0 & 0 & 0 & 1 & 0 & 0 & 0 & 0 & 0 & 0 \\
\hline Winter auction & 0 & 0 & 0 & 0 & 0 & 0 & 0 & 0 & 0 & 0 & 1 & 0 \\
\hline $\begin{array}{l}\text { National and reli- } \\
\text { gious celebrations } \\
\text { auction }\end{array}$ & 0 & 0 & 0 & 0 & 0 & 0 & 0 & 0 & 1 & 0 & 0 & 1 \\
\hline
\end{tabular}

the price of the bag has decreased from 40 to 32 , the price of the shoes has decreased from 35 to 24.5 and the price of clothes has decreased from 100 to 80. The price of bags and shoes and clothes reached 34, 29.8 and 85 in period 9 and also reached 32, 28 and 80 in period 12, respectively. The results of Tables 12 and 13 are similarly obtained. In Table 14, the optimum quantities of different products are expressed in different periods. Table 15 shows the percentage of satisfying demand per product at the end of the 12th period. In Table 16, all effective amounts in the total profit, including incomes and costs, are stated.

Figure 2 compares the initial demand, the actual demand and the satisfying demand through the main retailers for bags, shoes and clothes. Given the actual demand (demand variable) and the satisfying demand, the percentage of responsiveness to the demand by the main retailers for bags, shoes and clothes is $98.8 \%, 95.2 \%$ and $99.8 \%$, respectively. 
TABLE 11. Sales price per unit of product at the main retailers $\left(\mathrm{PRD}_{p t}\right)$.

\begin{tabular}{lllllllllllll}
\hline \hline \multirow{2}{*}{ Products } & \multicolumn{10}{c}{ Periods } \\
\cline { 2 - 11 } & 1 & 2 & 3 & 4 & 5 & 6 & 7 & 8 & 9 & 10 & 11 & 12 \\
\hline Bag & 40 & 40 & 40 & 40 & 40 & 32 & 40 & 40 & 34 & 40 & 32 & 32 \\
Shoes & 35 & 35 & 35 & 35 & 35 & 24.5 & 35 & 35 & 29.8 & 35 & 24.5 & 28 \\
Clothes & 100 & 100 & 100 & 100 & 100 & 80 & 100 & 100 & 85 & 100 & 80 & 80 \\
\hline
\end{tabular}

TABLE 12. Sales price per unit of product at the outlet retailers $\left(\mathrm{POD}_{p t}\right)$.

\begin{tabular}{lllllllllllll}
\hline \hline \multirow{2}{*}{ Products } & \multicolumn{10}{c}{ Periods } \\
\cline { 2 - 12 } & 1 & 2 & 3 & 4 & 5 & 6 & 7 & 8 & 9 & 10 & 11 & 12 \\
\hline Bag & 15 & 15 & 15 & 15 & 15 & 12 & 15 & 15 & 12.8 & 15 & 12 & 12 \\
Shoes & 20 & 20 & 20 & 20 & 20 & 14 & 20 & 20 & 17 & 20 & 14 & 16 \\
Clothes & 90 & 90 & 90 & 90 & 90 & 72 & 90 & 90 & 76.5 & 90 & 72 & 72 \\
\hline
\end{tabular}

TABLE 13. Sales price per unit of a product by the factory through the direct channel $\left(\mathrm{PDD}_{p t}\right)$.

\begin{tabular}{lllllllllllll}
\hline \hline \multirow{2}{*}{ Products } & \multicolumn{1}{c}{ Proriods } \\
\cline { 2 - 12 } & 1 & 2 & 3 & 4 & 5 & 6 & 7 & 8 & 9 & 10 & 11 & 12 \\
\hline Bag & 36 & 36 & 36 & 36 & 36 & 36 & 36 & 36 & 30.6 & 36 & 28.8 & 28.8 \\
Shoes & 31.5 & 31.5 & 31.5 & 31.5 & 31.5 & 22 & 31.5 & 31.5 & 26.8 & 31.5 & 22 & 25.2 \\
Clothes & 90 & 90 & 90 & 90 & 90 & 72 & 90 & 90 & 76.5 & 90 & 72 & 72 \\
\hline
\end{tabular}

TABLE 14. The amount of product produced in the factory $\left(\mathrm{QM}_{p t}\right)$.

\begin{tabular}{|c|c|c|c|c|c|c|c|c|c|c|c|c|}
\hline \multirow{2}{*}{ Products } & \multicolumn{12}{|c|}{ Periods } \\
\hline & 1 & 2 & 3 & 4 & 5 & 6 & 7 & 8 & 9 & 10 & 11 & 12 \\
\hline Bag & 48146 & 48146 & 48146 & 48146 & 48146 & 47791 & 48246 & 48146 & 47879 & 48146 & 47791 & 47931 \\
\hline Shoes & 42097 & 42097 & 42097 & 42097 & 42097 & 35503 & 421777 & 42097 & 38698 & 42097 & 35503 & 37608 \\
\hline Clothes & 33950 & 33950 & 33950 & 33950 & 33950 & 32628 & 34080 & 33950 & 33262 & 33950 & 33628 & 32798 \\
\hline
\end{tabular}

TABle 15. Percentage of satisfying demand.

\begin{tabular}{llll}
\hline \hline Products & Main retailers & Outlet retailers & Direct channel \\
\hline Bag & 98.8 & 100 & 100 \\
Shoes & 95.2 & 100 & 93.3 \\
Clothes & 99.8 & 100 & 96.9 \\
\hline
\end{tabular}


TABLE 16. Costs, incomes and profit of the supply chain.

\begin{tabular}{lll}
\hline \hline \multirow{2}{*}{ Incomes } & Sales through main retailers & 54975070 \\
& Sales through outlet retailers & 358766.3 \\
& Sales through the direct channel & 2609941 \\
\hline \multirow{2}{*}{ Costs } & Buying raw materials & 1861951 \\
& Sending raw materials from suppliers to the factory & 1138580 \\
& Production cost & 1300130 \\
& Sending products to main retailers & 2285876 \\
& Sending products to outlet retailers & 1482.6 \\
& Sending products from the main retailer to the outlet retailers & 234 \\
& Holding raw material stock at the factory & 0 \\
& Holding products stock at the factory & 0 \\
& Holding products stock at the main retailers & 0 \\
& Holding products stock at the outlet retailers & 0 \\
Sending products through the direct channel & 128849.6 \\
Direct channel operation & 7200 \\
\hline
\end{tabular}

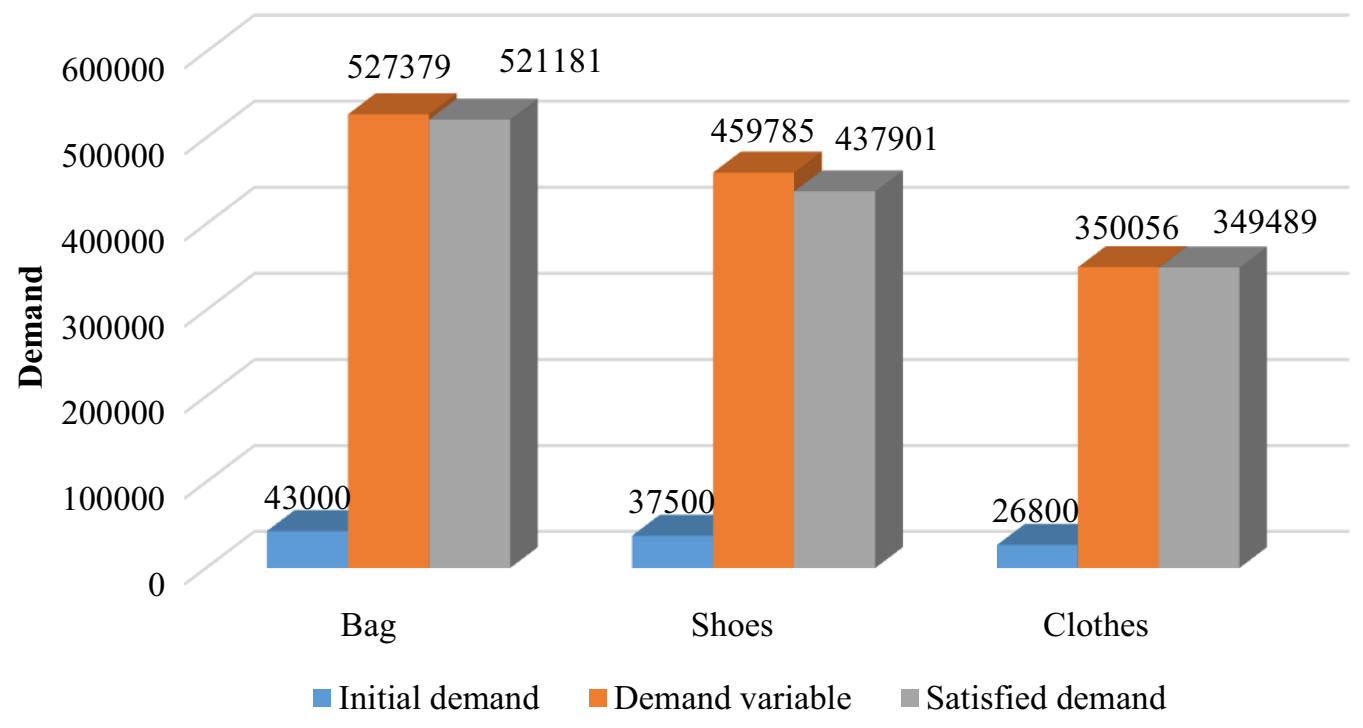

Figure 2. Comparison of initial demand, actual demand and satisfying demand to main retailers.

\subsection{Sensitivity analyses}

The sensitivity analyses of the model are studied by changing the important parameters of the problem. The sensitivity analyses examine the number of changes in the total profit, direct channel demand, the demand of the main retailers and the demand of the outlet retailers as a result of changing the input parameters of the problem.

\subsubsection{Sensitivity analysis of $\lambda_{1}$}

In Figure 3, the percentage of changes in the total demand of the main retailers and the total profit of the supply chain are shown by the changes in the value of $\lambda_{1}$. Since $\lambda_{1}$ has a negative coefficient in the demand 


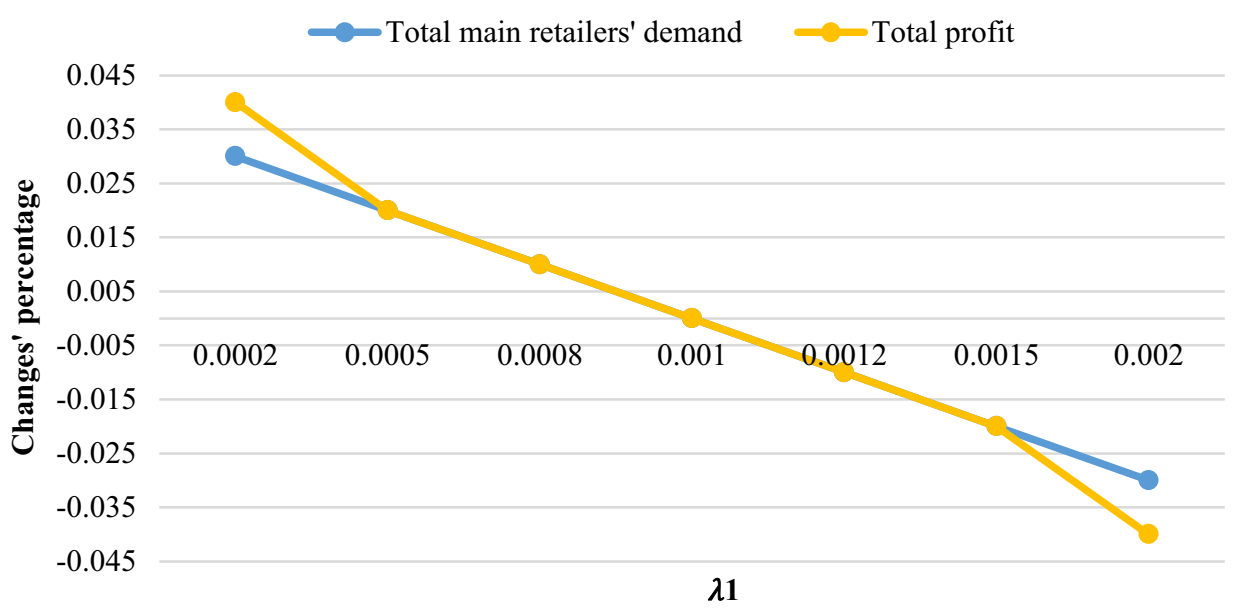

FIGURE 3. Effect of $\lambda_{1}$ on the percentage of changes in the total main retailers demand and the total profit.

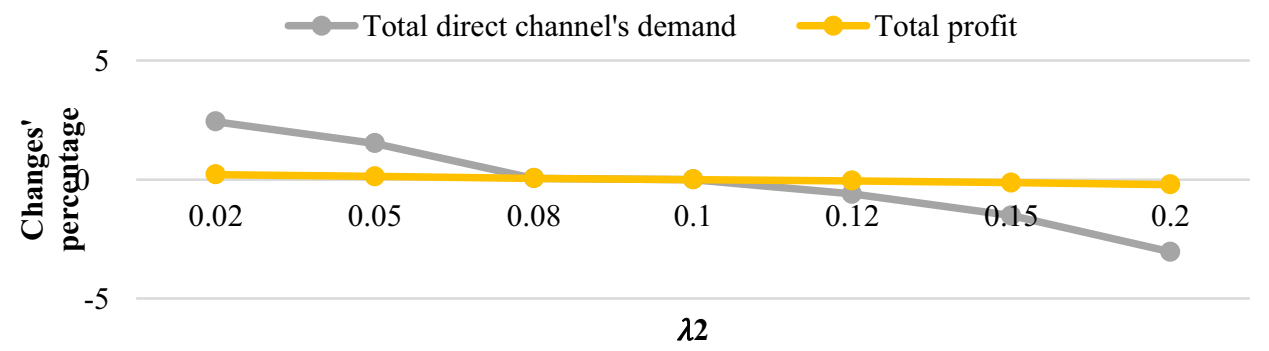

FiguRE 4. Effect of $\lambda_{2}$ on the changes in the total direct channel demand and the total profit.

formula of the main retailers, increasing its value reduces the demand and, as a result, reduces sales at the main retailers and thereby reduces the total profit of the supply chain. By contrast, reducing the amount of $\lambda_{1}$ will increase the main retailers demand and, as a result, increase the total profit of the supply chain. It can be noted that in Figure 3, two diagrams are overlapped and only differ at the beginning interval $\lambda_{1} \sim(0.0002,0.0005)$ and end interval $\lambda_{1} \sim(0.0015,0.002)$.

\subsubsection{Sensitivity analysis of $\lambda_{2}$}

In Figure 4, the percentage of changes in the direct channel demand and the supply chain total profit are shown related to changes in the value of $\lambda_{2}$. Since $\lambda_{2}$ has a negative coefficient in the direct channel demand formula, increasing its value reduces the demand and, as a result, it reduces direct channel sales, thereby reducing the overall supply chain profit.

However, it seems that the total direct channel demand changes with greater slope than the total profit regarding to the $\lambda_{2}$ changes. This indicates that the total direct channel demand is more sensitive to $\lambda_{2}$. The two diagrams are overlapped only in interval $\lambda_{2} \sim(0.08,0.1)$ and there is a sharp difference before and after this interval.

\subsubsection{Sensitivity analysis of $\gamma_{1}$}

In Figure 5, the percentage of changes in the total direct channel demand and the total profit of the supply chain are shown due to the changes in the value of $\gamma_{1}$. Since $\gamma_{1}$ has a positive coefficient in the direct channel 


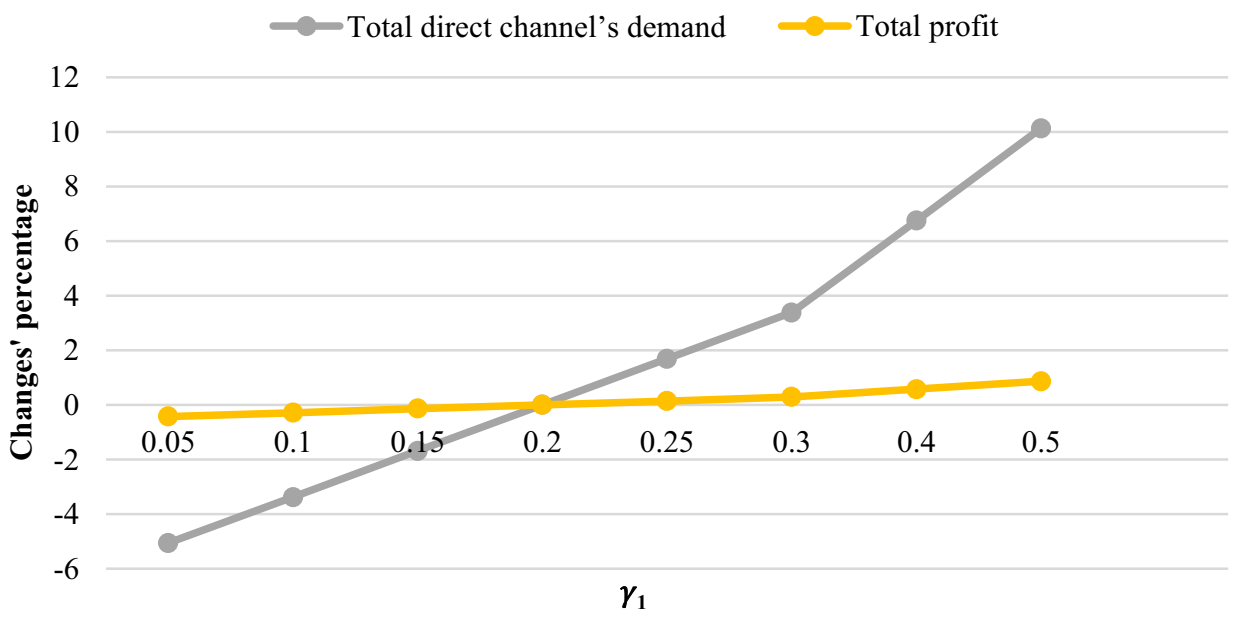

FIGURE 5. Effect of $\gamma_{1}$ on the changes in the total direct channel demand and the total profit.

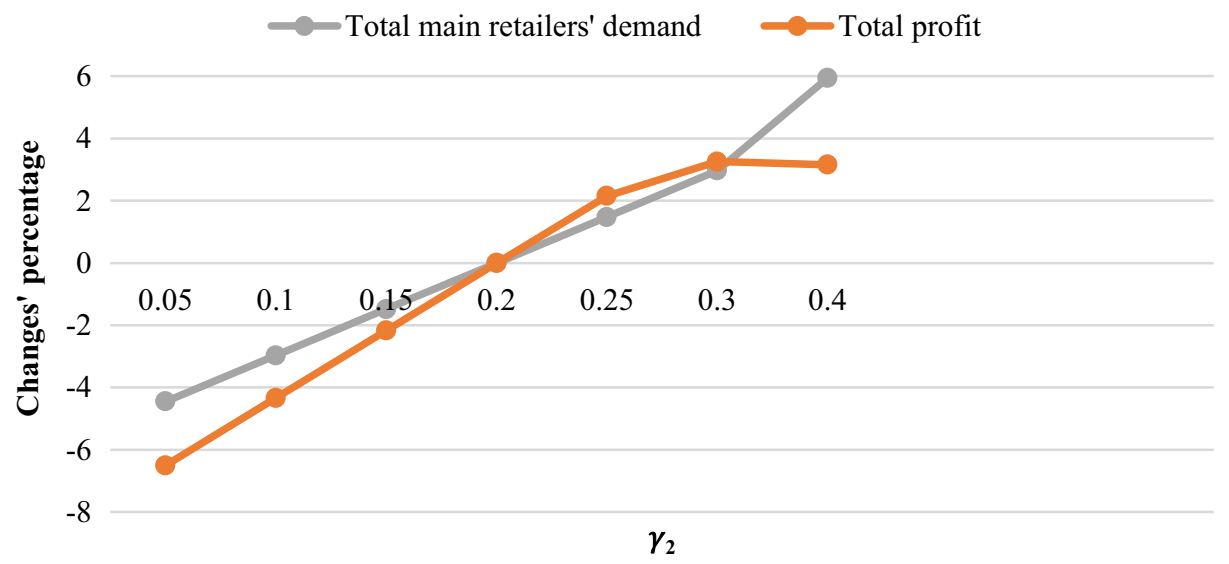

FiguRE 6 . Effect of $\gamma_{2}$ on the percentage of changes in the total main retailers demand and the total profit.

demand formula, increasing its value will increase demand and, as a result, increases direct channel sales, which will increase the total profit of the supply chain. By contrast, reducing the amount of $\gamma_{1}$ will reduce the direct channel demand and, consequently, reduce the overall supply chain profit.

\subsubsection{Sensitivity analysis of $\gamma_{2}$}

In Figure 6, the percentage of changes in the total retailers demand and the supply chain total profit are shown related to changes in the value of $\gamma_{2}$. Since $\gamma_{2}$ has a positive coefficient in the main retailer demand formula, increasing its value increases the demand. As a result, it increases the sales of the main retailers and thus the total profit of the supply chain increases. In contrast, reducing $\gamma_{2}$ reduces the main retailers demand and thereby reduces the total supply chain profit. 


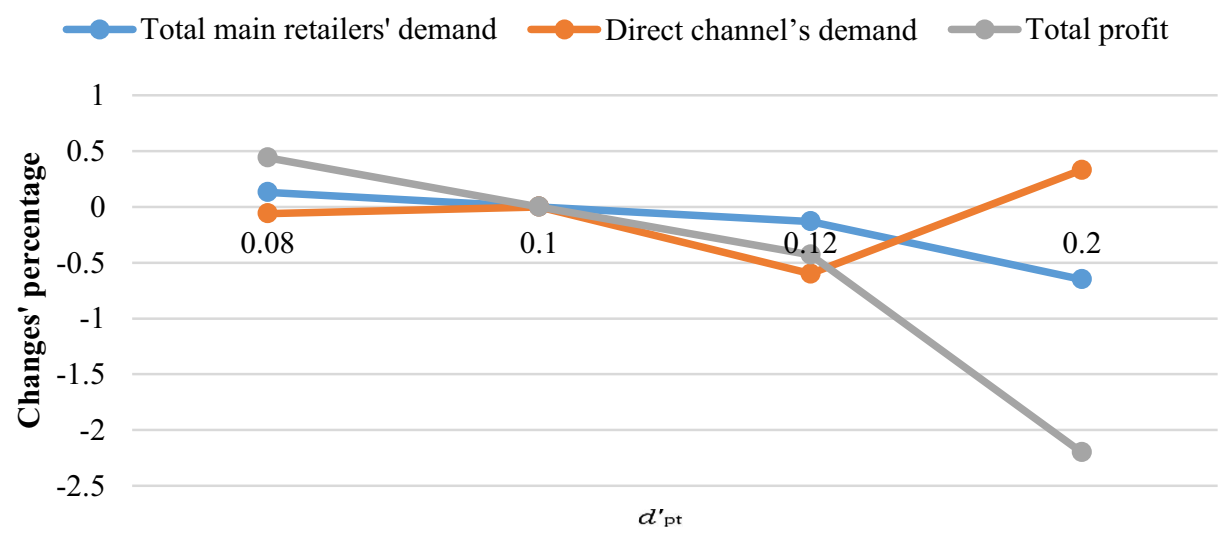

FIGURE 7. Effect of $d_{p t}^{\prime}$ on changes in demand of the total main retailers, direct channel and total profit.

TABLE 17. Effect of $\mu$ on changes in the total outlet retailers demand and total profit of the SC.

\begin{tabular}{llllllll}
\hline \hline $\begin{array}{l}\text { Percentage of } \\
\text { changes in the }\end{array}$ & \multicolumn{7}{c}{$\mu$} \\
\cline { 2 - 8 } & 0.4 & 0.5 & 0.6 & 0.7 & 0.8 & 0.9 & 1 \\
\hline $\begin{array}{l}\text { Total outlet retailers' } \\
\text { demand }\end{array}$ & -2.48 & -1.65 & -0.83 & 0 & 0.83 & 1.65 & 2.48 \\
$\begin{array}{l}\text { Total profit of the } \\
\text { supply chain }\end{array}$ & -0.03 & -0.02 & -0.01 & 0 & 0.01 & 0.02 & 0.03 \\
\hline
\end{tabular}

\subsubsection{Sensitivity analysis of $\boldsymbol{d}_{\boldsymbol{p t}}^{\prime}$}

Figure 7 shows the percentage of changes in the total retailers demand, direct channel demand and the total profit of the supply chain due to the changes in the value of $\boldsymbol{d}_{\boldsymbol{p} \boldsymbol{t}}^{\prime}$. As shown in Figure 7 , by decreasing the value of $\boldsymbol{d}_{p t}^{\prime}$ from 0.1 to 0.08 , the percentage of direct channel demand decreases as well as the percentage of the total retailer channel's demand and the total profit increases. By increasing the value of $\boldsymbol{d}_{p t}^{\prime}$ from 0.1 to 0.12 , the percentage of the direct channel demand and the total retailers demand decrease that results in a decrease in the total profit. By increasing the value of $\boldsymbol{d}_{p t}^{\prime}$ from 0.12 to 0.2 , the direct channel demand increases and reduces the total retailers demand, as a result, the total profit reduces. Thus, increasing direct channel discounts will not always increase the channel demand and profitability, as customers may migrate to competitors instead of buying from two existing channels which its' impact on the current model supply chain is not taken into account.

\subsubsection{Sensitivity analysis of $\mu$}

Table 17 shows the percentage of changes in the total outlet retailers demand and the total profit of the supply chain due to the changes in the value of $\mu$. Increasing or decreasing the value of $\mu$ has a direct impact on the total outlet retailers demand and the total supply chain (SC) profit.

This table shows that by increasing this parameter from 0.7 to 1 , we are observing positive changes in the total outlet retailers demand and total profit. Accordingly, by decreasing $\mu$ from 0.7 to 0.4 , we are seeing negative changes in these variables. As can be seen, changes in $\mu$ cause similar changes in these two variables. However, the rate of change in the total outlet retailers demand is greater than the total profit of the supply chain. 


\subsection{Managerial insights}

The purpose of this study was to consider the importance of the leather supply chain network that has created a discounted online channel to sustain its market share. This plan can help to maximize their profits and examine the effect of different discounts on demand and sales. Furthermore, applying the suggested model can make significant contributions to the supply chain managers in strategic decisions. In the following, some managerial insights are reported based on the gained results to improve the supply chain.

According to the results analyses, the number of satisfied demand in the main retailers was less than the demand and lost sales due to the low product availability in the main retailers was proven. Therefore, increasing the inventory of the main retailers can reduce the lost sales. Increasing the discount on the direct sales channel will shift the demand from retailers to the direct channel. Similarly, decreasing the discount level will shift the demand from the direct channel to the retailer channel. Therefore, increasing the percentage of discounts on the direct channel has a negative effect on the total profit of the supply chain. It is recommended to reduce this percentage from $10 \%$ to $8 \%$ that may increase the total profit. On the other hand, the number of lost sales in the supply chain can be reduced by creating different pricing and discount schemes such as incentive schemes and customer classification based on their purchase amounts.

Moreover, one of the important issues in selling products is to properly locating the retailers. For example, the tourist target market, where many Iranian and foreign tourists visit it, may have the potential to open more main and outlet retailers.

\section{Conclusion}

With the rapid growth of the Internet, many factories became interested in establishing an electronic channel in addition to the traditional retailer channel to market. Some factories also sell some of their products through the site in addition to selling through their retailers. In recent years, due to the increasing consumption and interest of consumers in buying leather products due to their quality, variety, beauty and durability, their market for production and sale has increased. In this way, many factories and workshops have made leather products. In the direct channel, the product is shipped to them based on the amount of inventory and customers' order and the sales through the indirect channel are through the main retailer and outlet retailer. Outlet retailers sell some products that are outdated, either slightly damaged during production, or have high warehousing costs sell at a lower price to zero at the factory.

In this study, a leather supply chain network has been developed to create a discounted online channel to maintain its market share. To this end, a multi-period and multi-product mathematical model has been developed to investigate the effect of different discounts on demand and sales. To evaluate the proposed model, a real case study has been conducted. By collecting data related to the input parameters, the mathematical model is solved and the results are presented.

The proposed model can be extended in several practical directions. Due to the increasing attention to environmental aspects and the integration of forward and reverse logistics, developing the proposed dual-chain supply chain by closed-loop flows can be investigated in future studies. Correspondingly, due to the complexity of the proposed model in the closed-loop mode, developing related heuristic algorithms can be recommended.

\section{REFERENCES}

[1] M. Amini and H. Li, The impact of dual-market on supply chain configuration for new products. Int. J. Prod. Res. 53 (2015) 5669-5684.

[2] A. Arabsheybani, M.M. Paydar and A.S. Safaei, An integrated fuzzy MOORA method and FMEA technique for sustainable supplier selection considering quantity discounts and supplier's risk. J. Clean. Prod. 190 (2018) 577-591.

[3] F. Barzinpour and P. Taki, A dual-channel network design model in a green supply chain considering pricing and transportation mode choice. J. Intell. Manuf. 29 (2018) 1465-1483.

[4] K. Campo and E. Gijsbrechts, Should retailers adjust their micro-marketing strategies to type of outlet? An application to location-based store space allocation in limited and full-service grocery stores. J. Retail. Consum. Serv. 11 (2004) 369-383. 
[5] A. Cheraghalipour, M.M. Paydar and M. Hajiaghaei-Keshteli, Applying a hybrid BWM-VIKOR approach to supplier selection: a case study in the Iranian agricultural implements industry. Int. J. Appl. Decis. Sci. 11 (2018) 274-301.

[6] A. Cheraghalipour, M.M. Paydar and M. Hajiaghaei-Keshteli, Designing and solving a bi-level model for rice supply chain using the evolutionary algorithms. Comput. Electron. Agric. 162 (2019) 651-668.

[7] W.K. Chiang, D. Chhajed and J.D. Hess, Direct marketing, indirect profits: a strategic analysis of dual-channel supply-chain design. Manage. Sci. 49 (2003) 1-20.

[8] D.L. Duffy, Multi-channel marketing in the retail environment. J. Consum. Mark. 21 (2004) 356-359.

[9] D. Fan, Q. Xu, T. Fan and F. Cheng, Inventory optimization model considering consumer shift and inventory transshipment in dual-channel supply chains. RAIRO:OR 53 (2019) 59-79.

[10] F.S. Hillier and G.J. Lieberman, Introduction to Operations Research, 7th edition. McGraw-Hill Education, New York, NY (2001).

[11] C.-L. Hsieh, S.-H. Liao and W.-C. Ho, Multi-objective dual-sale channel supply chain network design based on NSGA-II. In: Modern Advances in Applied Intelligence. IEA/AIE 2014. Springer, Cham (2014) 479-489.

[12] S. Huang, X. Guan and B. Xiao, Incentive provision for demand information acquisition in a dual-channel supply chain. Transp. Res. Part E Logist. Transp. Rev. 116 (2018) 42-58.

[13] H. Jafari, S.R. Hejazi and M. Rasti-Barzoki, Pricing decisions in dual-channel supply chain with one manufacturer and multiple retailers: a game-theoretic approach. RAIRO:OR $\mathbf{5 1}$ (2017) 1269-1287.

[14] M.-B. Jamali and M. Rasti-Barzoki, A game theoretic approach for green and non-green product pricing in chain-to-chain competitive sustainable and regular dual-channel supply chains. J. Clean. Prod. 170 (2018) 1029-1043.

[15] T. Javadi, N. Alizadeh-Basban, S. Asian and A. Hafezalkotob, Pricing policies in a dual-channel supply chain considering flexible return and energy-saving regulations. Comput. Ind. Eng. 135 (2019) 655-674.

[16] Q.-H. Li and B. Li, Dual-channel supply chain equilibrium problems regarding retail services and fairness concerns. Appl. Math. Model. 40 (2016) 7349-7367.

[17] T. Li and J. Ma, Complexity analysis of the dual-channel supply chain model with delay decision. Nonlinear Dyn. 78 (2014) 2617-2626.

[18] B. Li, W. Chen, C. Xu and P. Hou, Impacts of government subsidies for environmental-friendly products in a dual-channel supply chain. J. Clean. Prod. 171 (2018) 1558-1576.

[19] S.-H. Liao, C.-L. Hsieh and W.-C. Ho, Multi-objective evolutionary approach for supply chain network design problem within online customer consideration. RAIRO:OR 51 (2017) 135-155.

[20] N.M. Modak and P. Kelle, Managing a dual-channel supply chain under price and delivery-time dependent stochastic demand. Eur. J. Oper. Res. 272 (2019) 147-161.

[21] M.A. Moktadir, S.M. Ali, R. Rajesh and S.K. Paul, Modeling the interrelationships among barriers to sustainable supply chain management in leather industry. J. Clean. Prod. 181 (2018) 631-651.

[22] Y. Moon, T. Yao and T.L. Friesz, Dynamic pricing and inventory policies: a strategic analysis of dual channel supply chain design. Serv. Sci. 2 (2010) 196-215.

[23] N. Nekoiemehr, G. Zhang and E. Selvarajah, Due date quotation in a dual-channel supply chain. Int. J. Prod. Econ. 215 (2019) 102-111.

[24] A. Ranjan and J.K. Jha, Pricing and coordination strategies of a dual-channel supply chain considering green quality and sales effort. J. Clean. Prod. 218 (2019) 409-424.

[25] B. Rosenbloom, Multi-channel strategy in business-to-business markets: prospects and problems. Ind. Mark. Manag. 36 (2007) $4-9$.

[26] M. Saidi-Mehrabad, M.M. Paydar and A. Aalaei, Production planning and worker training in dynamic manufacturing systems. J. Manuf. Syst. 32 (2013) 308-314.

[27] A.A. Taleizadeh, M.S. Moshtagh and I. Moon, Pricing, product quality, and collection optimization in a decentralized closedloop supply chain with different channel structures: game theoretical approach. J. Clean. Prod. 189 (2018) $406-431$.

[28] J. Xu, Q. Qi and Q. Bai, Coordinating a dual-channel supply chain with price discount contracts under carbon emission capacity regulation. Appl. Math. Model. 56 (2018) 449-468.

[29] J. Yu, M. Gan, S. Ni and D. Chen, Multi-objective models and real case study for dual-channel FAP supply chain network design with fuzzy information. J. Intell. Manuf. 29 (2018) 389-403. 